\title{
A Systematic Review of Nonpharmacological Exercise-Based Rehabilitative Interventions in Adults Undergoing Allogeneic Hematopoietic Stem Cell Transplantation
}

\author{
M. Jarden \\ Department of Haematology, The University Hospital of Copenhagen, \\ The University Hospital's Centre for Nursing and Care Research,
}

Copenhagen

Denmark

\section{Introduction}

Allogeneic hematopoietic stem cell transplantation (allo-HSCT) is an established treatment. More than 15,000 procedures are performed worldwide each year for a number of hematological malignancies such as acute myeloid and lymphoid leukemia, and bone marrow failure syndromes (Gratwohl et al. 2002; Frassoni, 2004). It is predicted that transplantation rates for allo-HSCT will continue at the same or higher level in the immediate future (Gratwohl et al. 2002). Despite clinical cure in $20-70 \%$ of all patients, depending on disease presentation, long term sequelae of immunosuppression, chemotherapy toxicities and graft-versus-host disease (GvHD) debilitate a large number of patients (Gratwohl et al. 2002). Moderate to severe GvHD develops in 40-50\% of patients undergoing allo-HSCT (Bearman et al. 1988; Weisdorf et al. 1990; Roy et al. 1992; Hings et al. 1994). Factors limiting the efficacy of this treatment are death due to recurrence or treatment-related death due to infection or organ failure in the cytopenia and later immunosuppressed phase immediately post-HSCT. Over the last decades, the cumulative effects of improvements in supportive care, drug dosing, stem cell technology and prophylaxis of GvHD have led to an increased number of complete remissions (Devergie, 2004). However, with the increasing number of transplants performed and the growing number of survivors, a shift in clinical focus from not only improving survival but also improving short and long-term quality of life has emerged (Andrykowski et al. 1995). Patients in the treatment and recovery phase of HSCT commonly experience adverse physical and emotional reactions. Fatigue and muscle weakness can limit ability to accomplish activities of daily living. Additionally, depression, anxiety, fear, and frustration add to the difficulties of recovering from HSCT (Syrjala et al. 1993; Andrykowski et al. 1995). Several studies confirm that high levels of physical and psychological stress have been observed in patients prior to and at the start of HSCT and during follow-up periods (Baker et al. 1997; Molassiotis \& Morris, 1997; McQuellon et al. 1998; Fife et al. 2000). The mechanisms are not fully known, but it is assumed that several factors such as total body 
irradiation (TBI), chemotherapy, GvHD, infections, long-term inactivity or bed rest and sideeffects from medication can contribute to the physical and emotional weakening of the patient. Recipients of allo-HSCT with low Vitamin D levels and low bone mineral density were likely to have received corticosteroids, have experienced GVHD and an elevated parathyroid hormone level (Sproat et al. 2011; Massenkeil et al. 2001). Vitamin D insufficiency and deficiency can cause osteomalacia, bone pain, muscle weakness, musculoskeletal pain, headache, fatigue, and may precipitate or exacerbate osteopenia and osteoporosis and increase risk of skeletal fracture (Knutsen et al. 2010; Sproat et al. 2011).

Patients that have undergone HSCT experience treatment-related symptoms during and after treatment that can affect health related quality of life (HR-QOL). Patients experience multiple somatic, affective and cognitive symptoms during and after aggressive cancer treatment, where eleven to thirteen simultaneously occurring symptoms have been reported (Portenoy et al. 1994). During hospitalization for standard allo-HSCT, patients are typically on prolonged bed rest, and experience complications from the myeloablative treatment, ie. acute GvHD, side effects from medications (immunosuppression \& steroids), frequent infections and psychological reactions that can be debilitating. It is reported that HR-QOL is lowest during inpatient time (Grulke et al. 2011). The most commonly reported symptoms are fatigue, diarrhea, insomnia, poor appetite, diminished concentration, mouth dryness, dyspnoea, loss of hair and poor body image perception (Jarden et al. 2009; Molassitis et al.1997; Larsen et al. 2007). After HSCT, fatigue, dyspnoea and insomnia remain at elevated levels (Grulke et al. 2011). Psychosocial wellbeing after transplant is influenced by mucositis toxicity, and other side effects, and psychological factors as anxiety, distress and social support have a significant impact on how severely patients experience mouth pain (SchulzKindermann et al. 2002) Fatigue is one of the most frequent and distressful side effects reported by patients who have undergone HSCT (Jarden et al. 2009; So et al. 2003), and it has been shown that physical activity decreased and this decline coincided with diminished physical, emotional, role and cognitive functioning during the initial post transplantation period (Danaher et al. 2006). Bevans et al. found that patients experienced multiple symptoms and high symptom distress after allo-HSCT conditioning (Bevans et al. 2008) Further, fatigue was the main symptom interfering with daily life in $79 \%$ of patients (Molassiotis \& Morris, 1999), and in 11\% of patients at 100 days post allo-HSCT (Bevans et al. 2008). Loss of physical strength seem to be more pronounced in patients on corticosteroid treatment, and the causes of an impairment of physical performance are not fully understood, though low activity levels have been suggested to be a substantial contributor (Carlson et al. 2006). One study in patients undergoing HSCT showed a correlation between the number of symptoms experienced and poor functional status and general health (Larsen et al. 2007) and in another study, changes in HRQoL could be explained entirely by changes in functional limitations and somatic symptoms (Broers et al. 2000). Further, symptom bother from GVHD had a direct effect on functional performance (Mitchell et al. 2010). A Danish study found patients prior to allo-HSCT to have lower $\mathrm{VO}_{2}$ max scores and elevated fatigue levels than the normal population, and these scores were unchanged six months after transplantation (Kalo et al. 2007). Furthermore, persons diagnosed with hematological disease have difficulty returning to the work force (deBoer et al. 2008) and have an increased risk for early retirement (Carlsen et al. 2008), while unemployed leukaemia patients, especially those with lower social support have significantly elevated levels of stress, anxiety, and depression (deBoer et al. 2008). In HSCT, predictors of slower return to work 
include physical dysfunction and female gender (Kirchhoff AC et al. 2010). Maintaining daily function and reducing fatigue and treatment-related symptoms can be important goals and there is therefore, a continued need for nonpharmacological strategies that address the specific impairments experienced by patients undergoing allo-HSCT.

There is a rapidly increasing literature on the effects of exercise on cancer rehabilitation, especially for breast cancer patients, on whom the majority of research has been conducted (Courneya et al. 2011, Conn et al. 2006). Despite that physical exercise showed positive effects on cardiorespiratory fitness, treatment-related symptoms and physiological effects, the extent of these positive results still need to be established. A qualitative and quantitative review and meta-analysis found only small to moderate effect of physical activity interventions on these outcomes (Schmitz et al. 2005; Conn et al. 2006). Physical activity is reported as being well tolerated in cancer survivors during and after treatment, however, conclusions about adverse effects are inconclusive (Schmitz et al. 2005). Recent guidelines for exercise prescription for cancer survivors from the American College of Sports Medicine (Schmitz et al. 2010) report no contraindication for starting an exercise program in patients undergoing either autologous or allogeneic HSCT - however, issues regarding, the ideal time for starting a program safely and effectively, type of program, frequency, intensity and duration is not confirmed, especially in relation to the HSCT treatment trajectory. Exercise has been proposed as a nonpharmacologic adjuvant therapy to combat the physiological and psychological symptoms of HSCT (Wiskemann \& Huber, 2008). However, little work exists in utilizing exercise interventions specifically in the allo-HSCT setting. It is documented that there is a decline in exercise levels in cancer patients from prediagnosis to postdiagnosis (Courneya et al.1997) and more specifically, a low level of "naturallyoccurring" exercise amongst patients undergoing HSCT is reported, suggesting that a structured intervention may be necessary in order to promote exercise in this population (Courneya et al. 2000). The majority of the earlier research done in adult patients with hematological disease is in the context of high dose chemotherapy with stem cell support (autologous HSCT or HD-SCS). To date, there are eight published studies that incorporated exercise regimes in the high dose chemotherapy-stem cell support context (HD- SCS) (Coleman et al. 2003; Decker et al 1989; Hayes et al. 2003, Dimeo et al. 1996, 1997, 1999, 2003, including one on-going study (Peerson et al. 2010), and five studies in mixed HD-SCS and allo-HSCT populations (Dimeo et al. 1999, Baumann et al. 2005; Wilson et al. 2005, Knols et al. 2010, Danaher Hacker et al. 2011). There are however fundamental and important differences in the two types of treatment (HD-SCS and allo-HSCT) including the conditioning regimes, i.e. total body irradiation in allo-HSCT, and origin of stem cells, i.e. patients undergoing HD-SCS are supported with their own stem cells, and therefore the donor related challenges (GvHD) in allo-HSCT are not present, and lastly, the overall duration of hospitalization for HD-SCS is much shorter compared to allo-HSCT. One 3 year prospective study, found that patients undergoing HD-SCS had better self-rated physical function (symptomotology, physical status and energy level) as compared to the allo-HSCT group (Prieto et al 2005). The HD-SCS and mixed group (HD-SCS and allo-HSCT, and age) exercise-based study sizes ranged between 12-70 participants. There are five randomized trials (Peerson et al. 2010; Baumann et al. 2005; Coleman et al. 2003; Hayes et al. 2004; Dimeo et al. 1996), one study used a minimization procedure (Knols et al. 2010) and six singlegroup trials (Danaher Hacker et al. 2011; Wilson et al. 2005; Decker et al 1989; Dimeo et al. 
1997, 1999, 2003). Exercise was tested during hospitalization in three studies ( Baumann et al. 2005; Dimeo et al. 1996; 2003), one study during hospitalization and continued to outpatient (Dimeo 1999), and eight studies after hospital discharge (outpatient and home based programs) (Wilson et al. 2005; Decker et al 1989; Coleman et al. 2003; Hayes et al. 2004; Dimeo et al. 1997, Knols et al. 2010; Peerson et al. 2010; Danaher Hacker et al. 2011). Feasibility was established, no adverse events registered and beneficial effects were reported on aerobic capacity (Hayes et al. 2004; Dimeo et al. 2003; Dimeo et al. 1996); muscle strength (Hayes et al. 2004; Knols et al. 2010), body composition (Coleman et al. 2003; Hayes et al. 2003), immunological function (Dimeo et al. 1997; Hayes et al. 2003; Knols et al. 2010), treatment-related symptoms i.e. fatigue (Dimeo et al. 1999; Wilson et al. 2005) and HRQoL (Wilson et al. 2005; Hayes et al. 2004). These positive and potentially important results for HD-SCS and mixed groups are encouraging, but we need to look exclusively at the alloHSCT adult patient group in order to evaluate the role and impact of exercise rehabilitation in this treatment context alone.

The primary objective of the systematic review is to summarize the exercise-based rehabilitative interventions in adults with haematological disease undergoing allogeneic hematopoetic stem cell transplantation (allo-HSCT) on feasibility and safety, and effectiveness related to physical and functional capacity, health related quality of life, treatment-related symptoms and medical related outcomes.

\section{Method}

The systematic literature search is based on PRISMA guidelines (preferred reporting items for systematic reviews and metaanalyses) developed from Cochrane Collaboration (Moher D et al. 2009).This review includes 1) a systematic literature search with the identification of all intervention trials in adult patients in the allo-HSCT setting during the past 25 years, 2) a uniform presentation of all trials and a synthesis of the characteristics and findings, 3) an appraisal of the methodological quality of the trials, 4) a summary and 5) conclusions and future research.

\subsection{Search strategy and data extraction}

The systematic literature review covers 25 years of research: 1986 - 2011 (Table 1). Searches were carried out in MEDLINE and EMBASE using search items bone marrow cell transplantation, bone marrow transplantation, stem cell transplantation, physical activity, physical fitness and exercise. Identified articles were searched for additional references. The search was limited to include randomized controlled trials (RCT), controlled clinical trials, adults and English articles. Eligibility criteria are shown in Table 2. Only studies that included patients from the allogeneic setting are included in this review. Studies that included patients in either the auto-HSCT / HD-SCS setting or mixed settings (both autologous and allogeneic) were excluded, though compiled in the literature search for background and reference purposes. Full articles were obtained for remaining abstracts and information was extracted from identified articles and organized under the following headings: authors, sample (n, type of treatment), age, design and study period, exercisebased intervention, duration, frequency/intensity, and results (Table 3). All articles were independently reviewed and appraised for rigor of method and analysis. 


\begin{tabular}{|l|l|l|l|l|}
\hline Date & Search & Limits & Database & Results \\
\hline $\mathbf{1 / 7 / 2 0 1 1}$ & "Bone Marrow Cell Transplantation" & English & Medline (NLM) & 90 \\
& $\begin{array}{l}\text { "Bone Marrow Transplantation" } \\
\text { "Stem Cell Transplantation" } \\
\text { Allogeneic[tw] } \\
\text { Autologous[tw] }\end{array}$ & $\begin{array}{l}\text { Publication date } \\
\text { from 1986/01/01 } \\
\text { to 2011/07/01 }\end{array}$ & & \\
& "Physical activity" & & \\
"Physical fitness" \\
"Exercise"
\end{tabular}

Table 1. Results of a systematic literature search with keywords

\section{Inclusion criteria}

\section{Exclusion criteria}

- Journal articles reporting primary research of $\bullet$ Studies that include auto-HSCT/HD-SCT exercise-based intervention studies prior to, $\bullet$ Studies that include a mixed population of during or after allo-HSCT auto-HSCT and allo-HSCT

- Randomized clinical trials or controlled studies

- Participants $\geq 18$ years

- Review articles or case study

- Recipients of allo-HSCT for a hematologic $\bullet$ Dissertations disease

- Conference abstracts

- Published in English between 1986 and 2011

- Editorials or letters to the editor

Allo-HSCT indicates allogeneic stem cell transplantation; auto-SCT, autologous stem cell transplantation; HD-SCT, high dose chemotherapy with stem cell support

Table 2. Eligibility criteria 


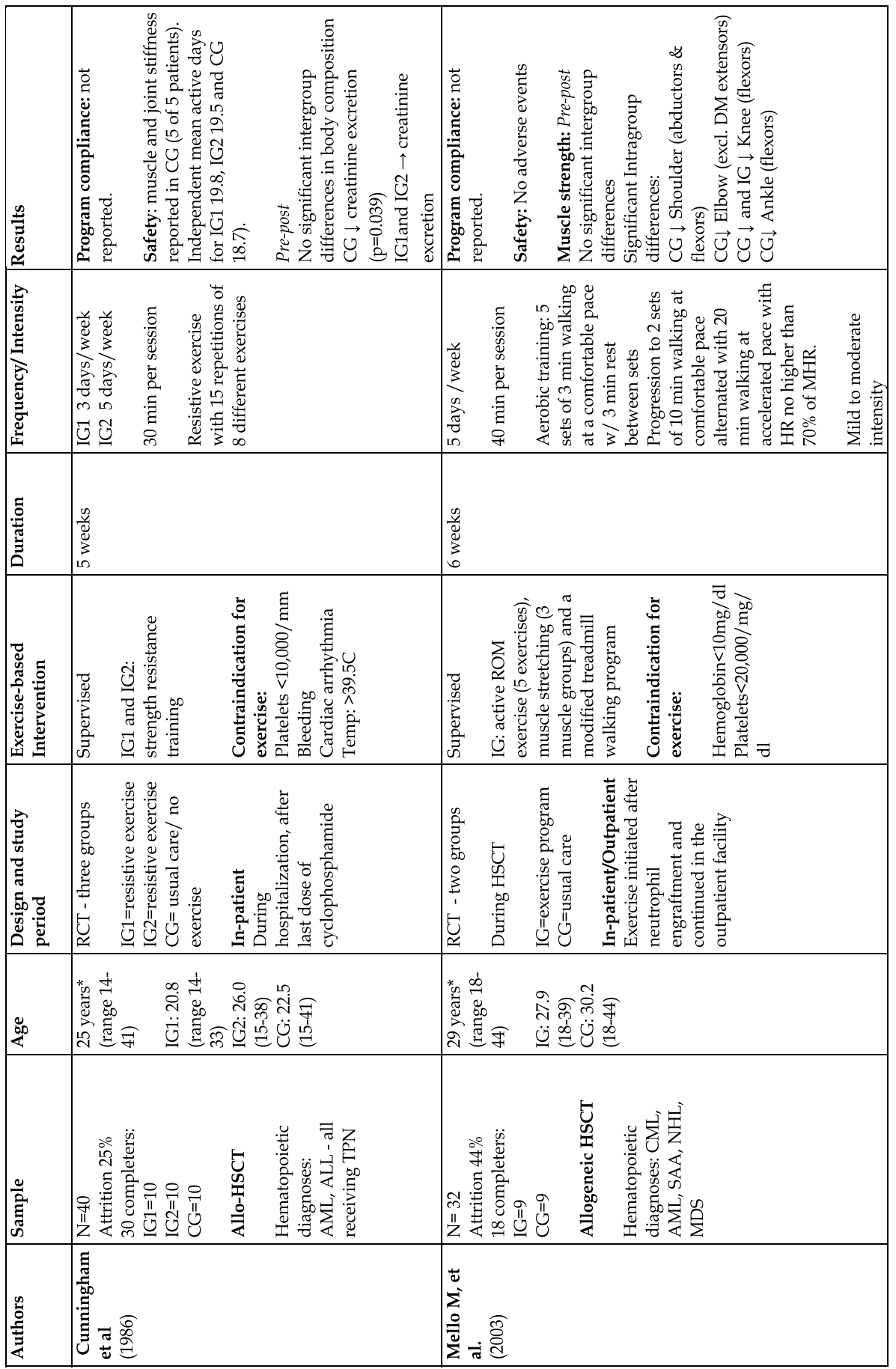




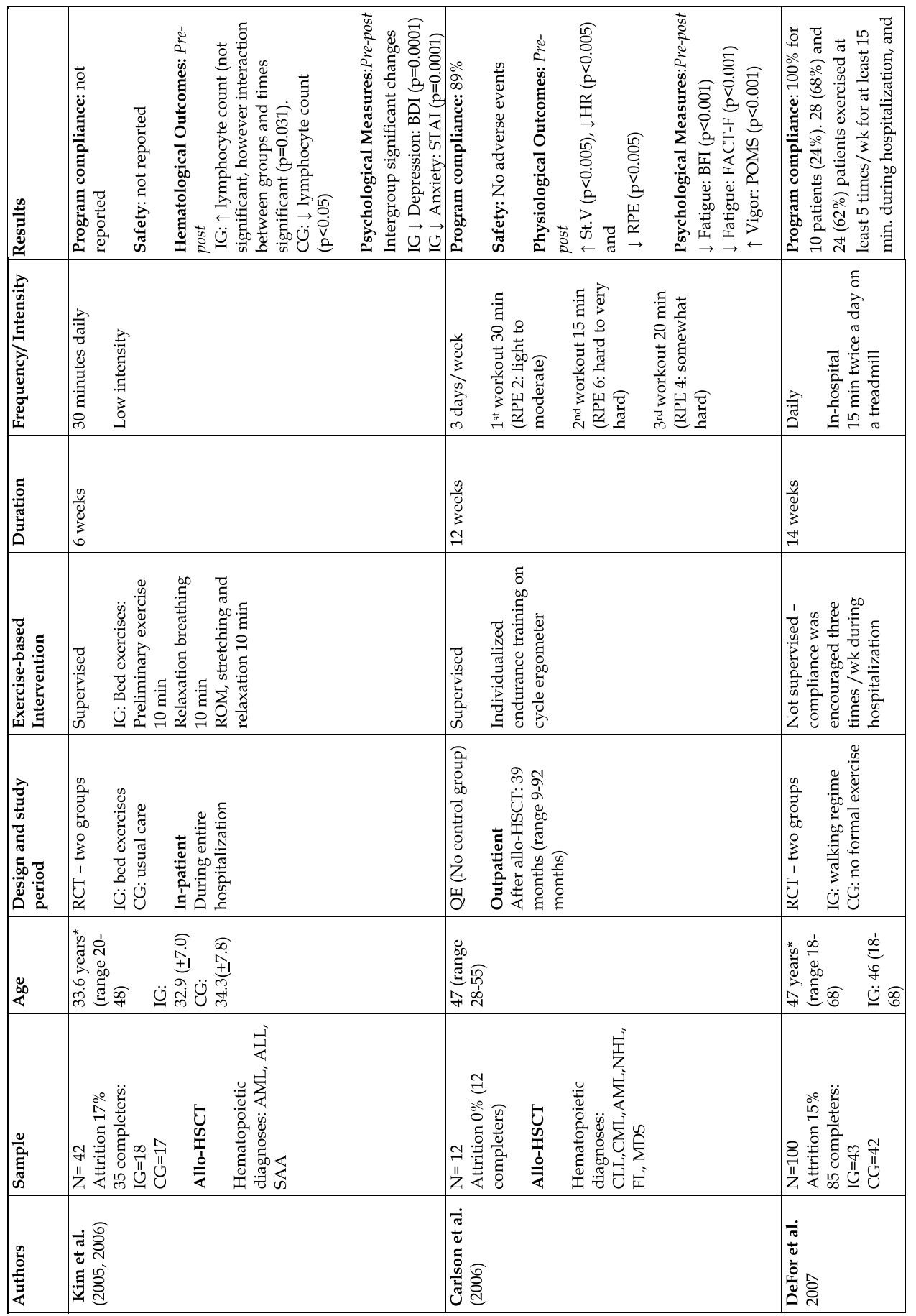




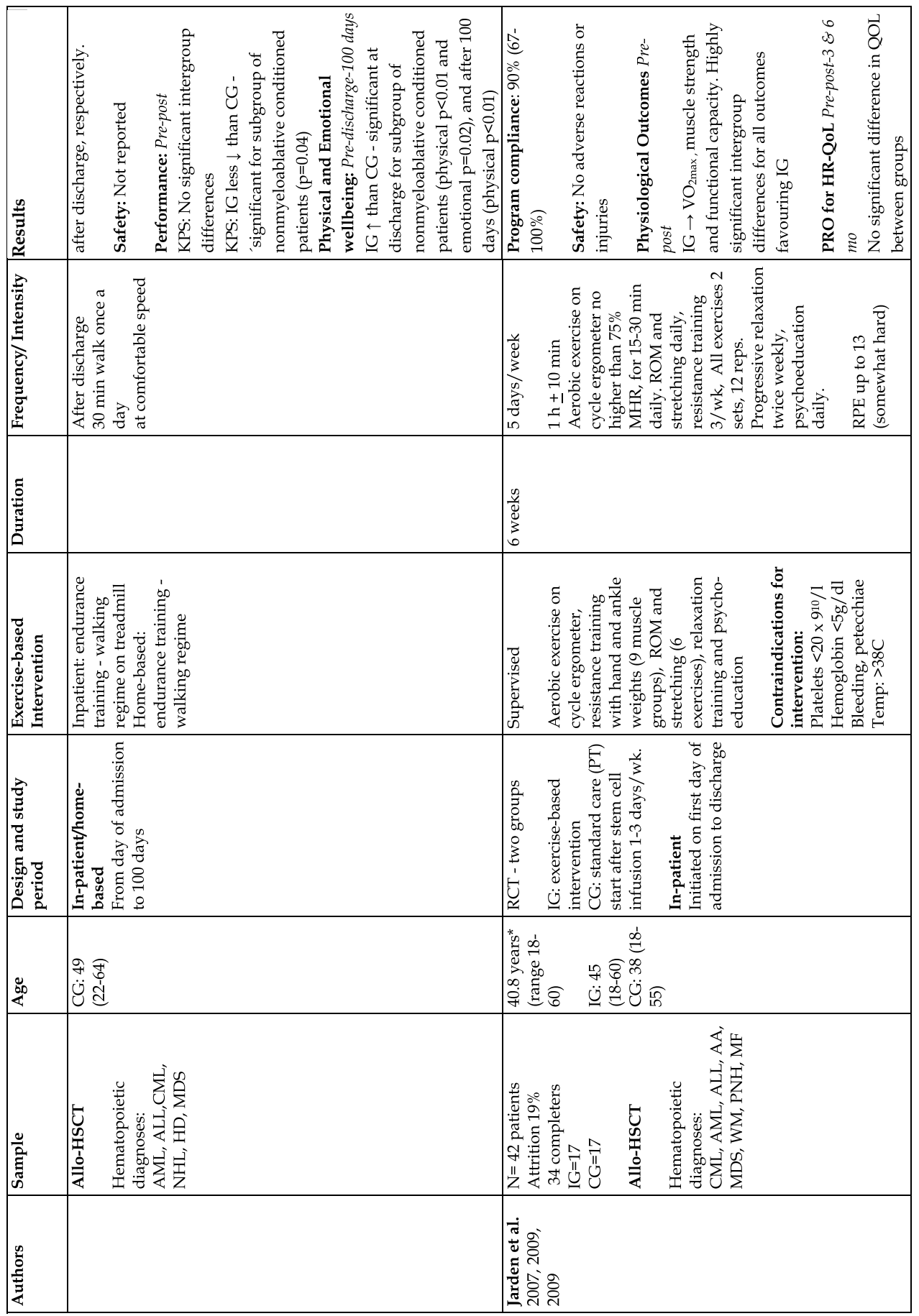




\begin{tabular}{|c|c|c|}
\hline 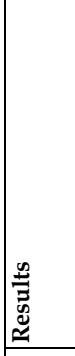 & 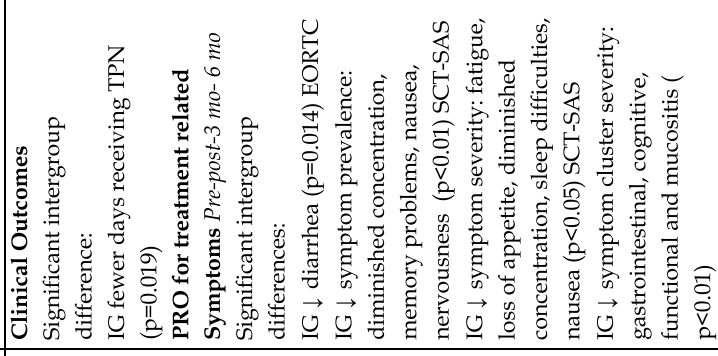 & 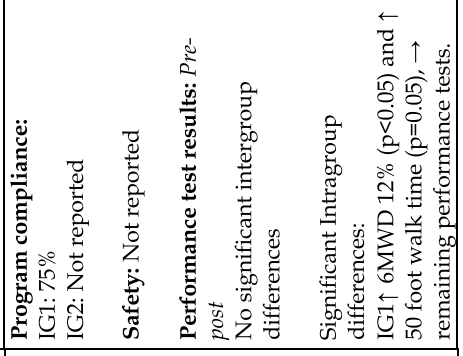 \\
\hline 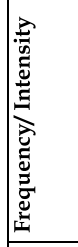 & & 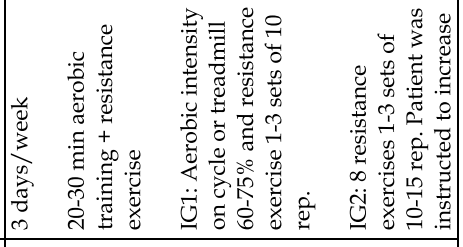 \\
\hline ڤే & & 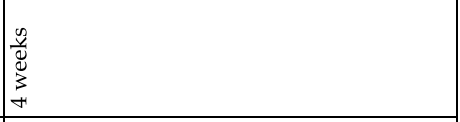 \\
\hline 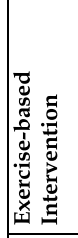 & & 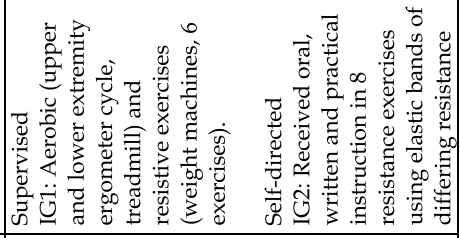 \\
\hline 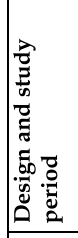 & & 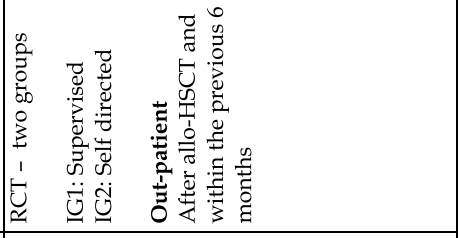 \\
\hline 总 & & 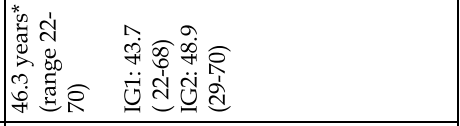 \\
\hline 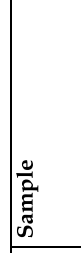 & & 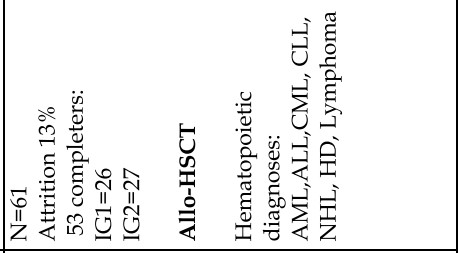 \\
\hline 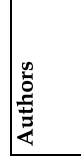 & & 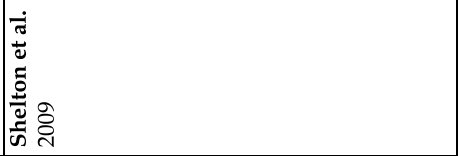 \\
\hline
\end{tabular}




\begin{tabular}{|c|c|c|c|}
\hline & 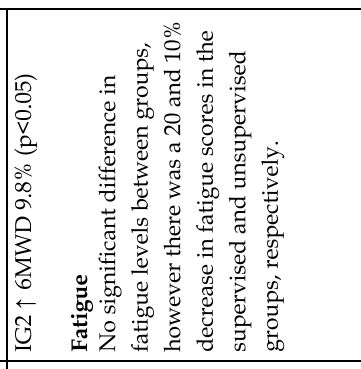 & 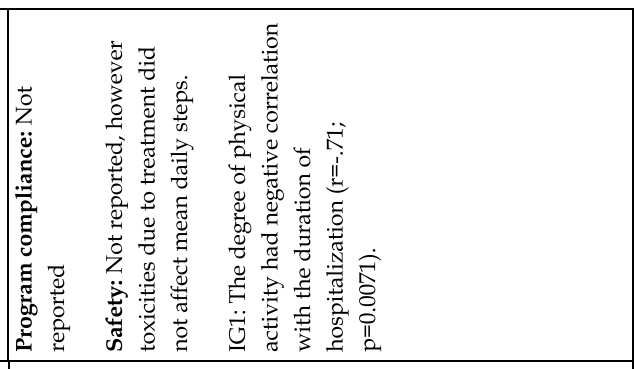 & 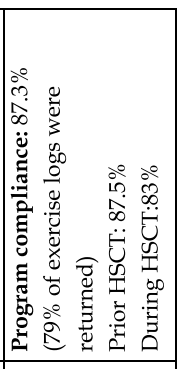 \\
\hline 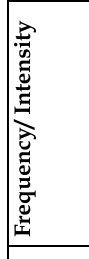 & 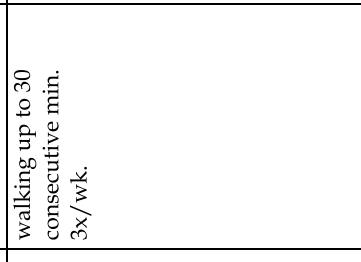 & 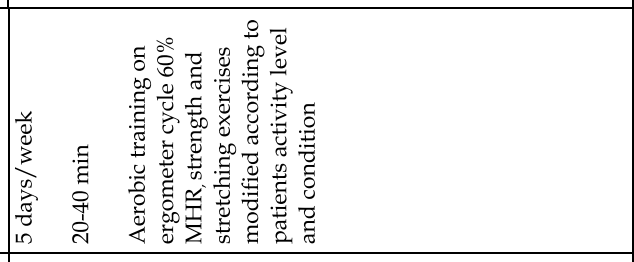 & 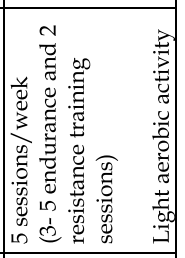 \\
\hline 㝴 & & 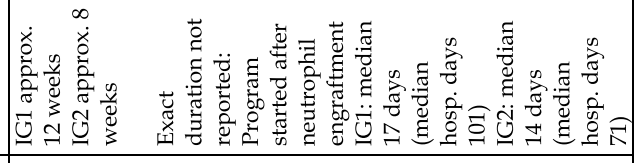 & 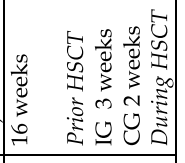 \\
\hline 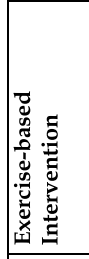 & 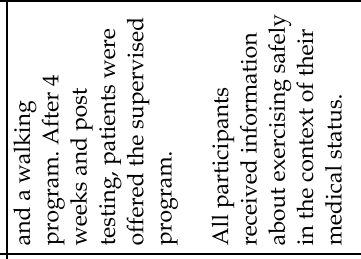 & 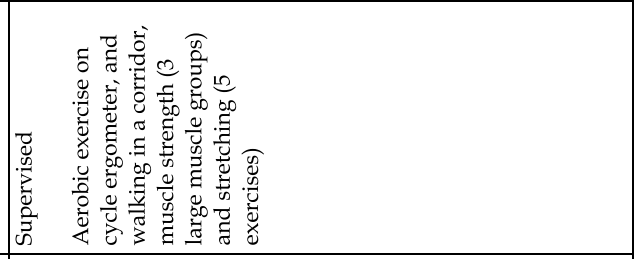 & 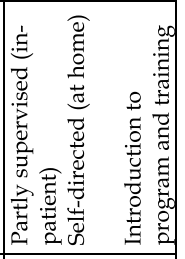 \\
\hline 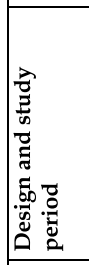 & & 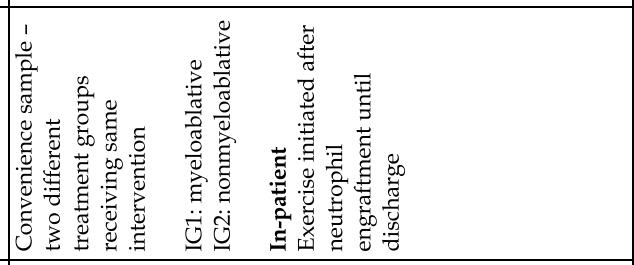 & 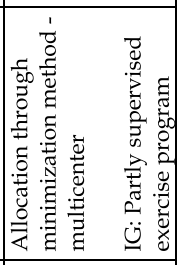 \\
\hline 8 & & 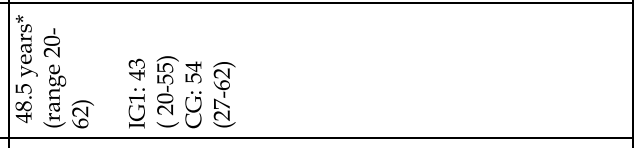 & 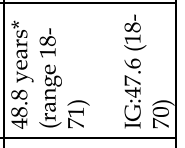 \\
\hline & & 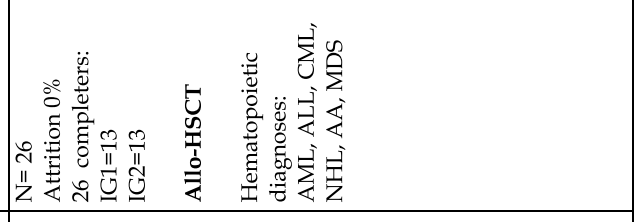 & 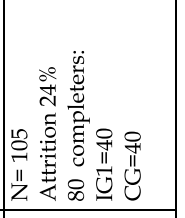 \\
\hline & & 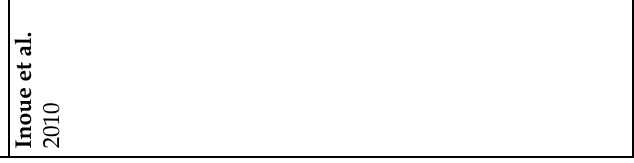 & 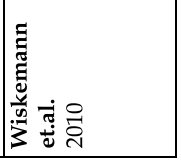 \\
\hline
\end{tabular}




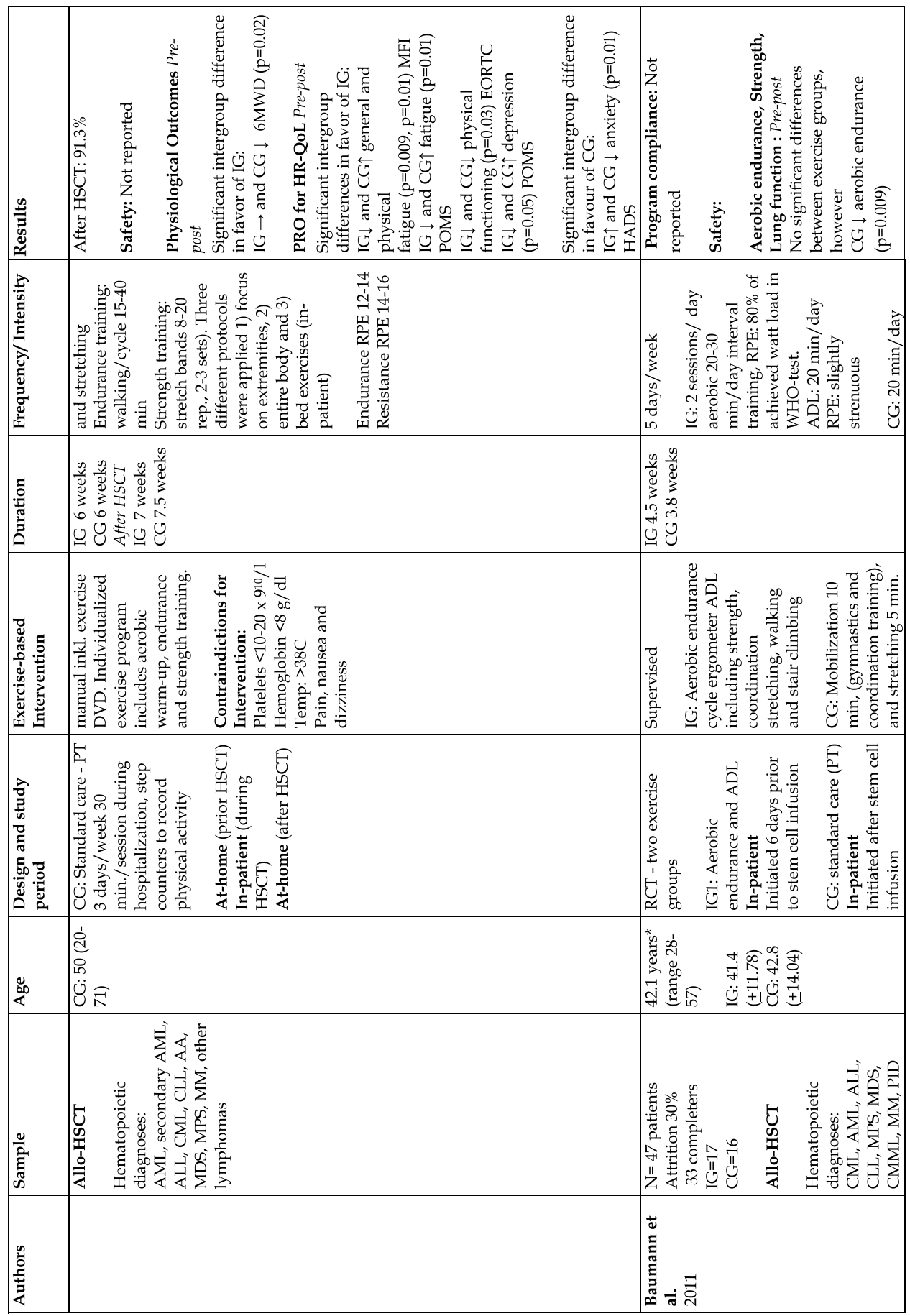




\begin{tabular}{|c|c|c|c|c|c|c|}
\hline Authors & Sample & Age & $\begin{array}{l}\text { Design and study } \\
\text { period }\end{array}$ & $\begin{array}{l}\text { Exercise-based } \\
\text { Intervention }\end{array}$ & Duration & Frequency/ \\
\hline & & & & $\begin{array}{l}\text { Contraindictions for } \\
\text { exercise: } \\
\text { Platelets }<10-20 \text { x 910/1 } \\
\text { Hemoglobin }<8 \mathrm{~g} / \mathrm{dl} \\
\text { Temp: }>38 \mathrm{C} \\
\text { Strong pain, infection, } \\
\text { restricted } \\
\text { consciousness, } \\
\text { somnolence, } \\
\text { confusion, dizziness, } \\
\text { nausea and vomiting. } \\
\text { Training was } \\
\text { interrupted during } \\
\text { cardio- and } \\
\text { nephrotoxic } \\
\text { chemotherapy. }\end{array}$ & & $\begin{array}{l}\text { RPE: Low ir } \\
\text { not strenuo }\end{array}$ \\
\hline
\end{tabular}

*median age

AA indicates aplastic anemia, AML, acute myelogenous leukemia; ALL, acute lymphocytic or lymphob lymphocytic leukemia; CML, chronic myelogenous leukemia; CMML, chronic myelomonocytic leukem myelodysplastic syndrome; MF, myelofibrosis; MM, multiple myeloma; MPS, myeloproliferative synd lymphoma; PNH, paroxysmal nocturnal hemoglobinuria; WM, waldenstrom macroglobulinemia RPE, Rate of Perceived Exertion; St.v, Stroke Volume; HR, Heart Rate; IG, Intervention Group; IG2, Inte Group; TPN, Total Parenteral Nutrition;

MHR, Maximal Heart Rate; DM and NDM, Dominant Non Dominant; KPS, Karnofsky Score; PT, Physi outcome; HR-QoL, health related Quality of Life; TR-symptoms, treatment related symptoms; SCT-SAS Symptom Assessment Scale; EORTC-QLQ-C30 European Organization for Research and Treatment of Questionnaire; HADS, Hospital Anxiety and Depression Scale; FACT-An or FACT-F, Functional Assess or Fatigue scale; POMS, Profile of Mood States; MFI, Multidimensional Fatigue Inventory; BFI, Brief Fa Depression Inventory; STAI, State Trait Anxiety Inventory; 6MWD, 6 minute walk distance , $\rightarrow$ no char 


\section{Results}

\subsection{Exercise-based studies in the allo-HSCT setting}

In this review, 10 studies met the inclusion criteria (Baumann et al. 2011; Carlson et al. 2006; Cunningham et al. 1986; Defor et al. 2007; Inoue et al., 2010; Jarden et al., 2009; Kim and Kim 2006; Mello et al. 2003; Shelton et al. 2009; Wiskemann et al. 2011). Of these, three were from the USA and two from Germany, and respectively, one from Brazil, Canada, Denmark, Japan and South Korea. Cunningham et al. carried out the very first exercise training trial for the allo-HSCT population in 1986 and although the participants included children and adults (range $14-41$ years), this study is included in the review because of its focus being in the allo-HSCT setting only. Jarden et al. published three articles and Kim et al. two articles, each based on one trial, however each article has a different focus and purpose.

All studies were designed as prospective intervention trials that tested an exercise-based program. The primary and secondary outcomes were study feasibility and safety; physiological outcomes i.e. aerobic, muscle strength and function; psychosocial outcomes i.e. health-related QoL, emotional wellbeing; treatment-related symptoms i.e. fatigue; and hospital or disease-related outcomes i.e. days of hospitalization, creatinine excretion, lymphocyte counts. Baseline to post assessment ranged between $4-16$ weeks [mean 7.3] and one study had follow-up tests to 6 months (Jarden et. al. 2009).

\subsection{Sample characteristics}

In all, 406 patients with different haematological diseases (AA, AML, ALL, CLL , CML, CMML, FL, HD, MDS, MF, MM, MPS, NHL, PNH, WM, other lymphomas) ${ }^{1}$ across 10

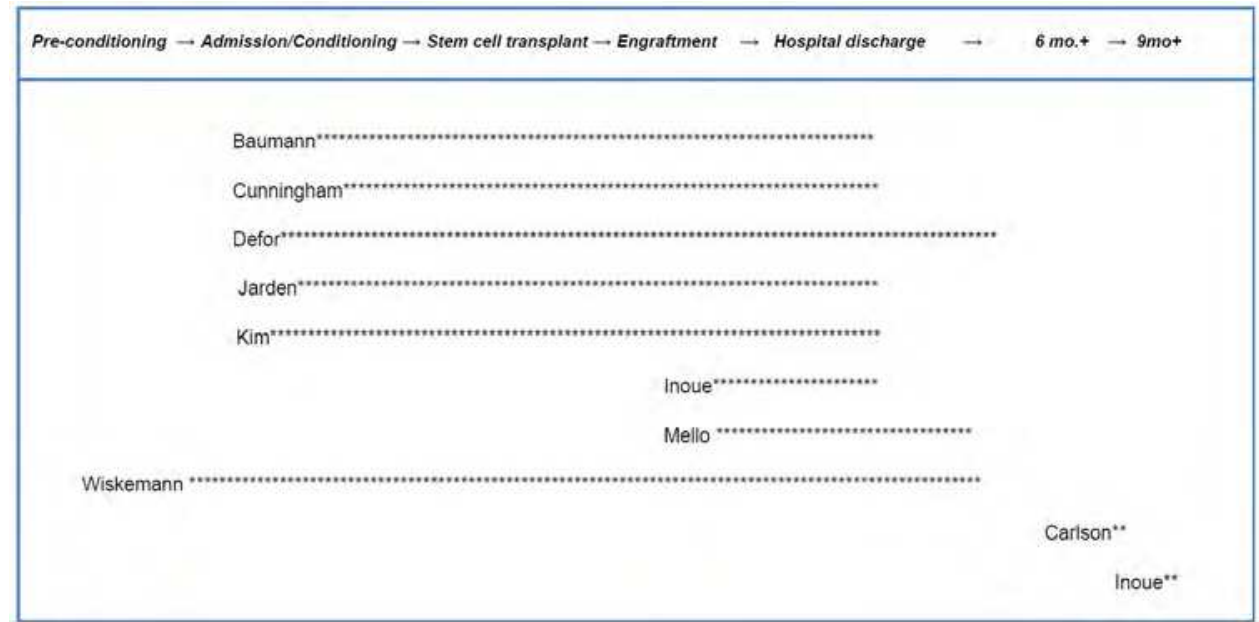

Table 4. Intervention phase

\footnotetext{
1 AA indicates aplastic anemia, AML, acute myelogenous leukemia; ALL, acute lymphocytic or lymphoblastic leukemia ; CLL, chronic lymphocytic leukemia; CML, chronic myelogenous leukemia; CMML, chronic myelomonocytic leukemia; HD, Hodgkins disease; MDS, myelodysplastic syndrome; MF, myelofibrosis; MM, multiple myeloma; MPS, myeloproliferative syndrome; NHL, Non-Hodgkin lymphoma; $\mathrm{PNH}$, paroxysmal nocturnal hemoglobinuria; WM, waldenstrom macroglobulinemia
} 
studies are included in this review. The sample size of the studies ranged from 12 to 105 [Mean 50.7] and the patients were of mixed gender between 14 and 71 years [mean 42.6]. Cunningham was the only study that included patients less than 18 years of age. Four studies were initiated prior to conditioning and throughout the hospitalization period (Baumann et al. 2011; Cunningham et al. 1986; Defor et al. 2007; Jarden et al. 2009; Kim and Kim 2006; Wiskemann et al. 2011), two studies after marrow engraftment and throughout hospitalization (Mello et al., 2003; Inoue et al., 2010), and three of these continued post alloHSCT (Defor et al. 2007; Mello et al. 2003; Wiskemann et al. 2011). Two studies were initiated post allo-HSCT in the out-patient or home setting, within 6 and 39 months (range 992), respectively (Shelton et al. 2009; Carlson et al. 2006). The approximate start and endpoint of each intervention is illustrated in Table 4.

\subsection{Type of exercise-based interventions}

The duration of the exercise-based interventions ranged between 4-16 weeks [mean 7.3]. For interventions initiated prior to and during hospitalization, 6 of the studies were supervised (Cunningham et al. 1986; Mello et al. 2003; Kim and Kim 2006; Jarden et al. 2009; Inoue et al. 2010; Baumann et al. 2011) and 2 were partly supervised (DeFor et al. 2007, Wiskemann et al. 2011). In the out-patient context, Carlson's study was fully supervised, while Shelton's study had one supervised and one self-directed study arm. The frequency of all interventions ranged between 3 and 5 days/week or daily. When reported, the intensity of training in general was between low/mild and comfortable to moderate but not exceeding $70-75 \%$ of maximum heart rate or in Rate of Perceived Exertion (RPE) - being somewhat hard.

In the in-patient context, one study tested strength resistive training (Cunningham et al. 1986), one a walking program (treadmill or walking) (Defor et al. 2007) and another mixedtype low intensity bed exercises of stretching and relaxation breathing (Kim and Kim 2006), and 5 studies instituted mixed-type exercise up to moderate intensity (Mello et al. 2003, Jarden et al. 2009, Inoue et al. 2010, Wiskemann et al. 2011, Baumann et al. 2011) by combining aerobic training (treadmill, cycle, walking or stair climbing) with one or more other moderate intensity exercise (range of motion or ADL (activities of daily living), coordination exercises, muscle stretching, resistive exercises with free weights or elastic bands) and low intensity progressive relaxation training and education (Jarden et al. 2009). Three studies (Mello et al. 2003; Wiskemann et al. 2011, Defor et al. 2007) continued the programs after hospital discharge. In the out-patient only context, one study tested an ergometer cycle program (Carlson et al. 2006), and the other, aerobic (cycle or treadmill) and resistive exercises (weight machines) vs. selfdirected walking and resistive exercises including patient information regarding exercise safety (Shelton et al. 2009). All in all, three studies were unidimensional (one exercise component), of which, two were aerobic training (Carlson et al. 2006; DeFor et al. 2007), and one resistance training (Cunningham et al. 1986), and seven studies had mixed type training (Baumann et al. 2011; Inoue et al. 2010; Jarden et al. 2009; Kim and Kim 2006; Mello et al. 2003; Shelton et al. 2009; Wiskemann 2011), of which, one was of low intensity (Kim and Kim 2006), and one study included both low and moderate intensity components (Jarden et al. 2009). Only two studies incorporated educational (Shelton et al. 2009) or psychoeducational (Jarden et al. 2009) elements in the program. 


\subsection{Feasibility and safety}

No adverse events, reactions or injuries were reported, though not all studies reported safety outcomes. The overall attrition rates ranged between 0 and $44 \%$ (mean 18.7). Program compliance was reported by five studies (Carlson et al. 2006; DeFor et al. 2007; Jarden et al. 2009; Shelton et al. 2009; Wiskemann et al. 2011). Carlson et al. reported an overall $89 \%$ compliance. Defor et al. reported that $24 \%$ of all patients had $100 \%$ compliance and that $62 \%$ of the study's population exercised at least 5 times/wk for at least $15 \mathrm{~min}$ during hospitalization and after discharge, respectively. Jarden et al. reported $90 \%$ intervention compliance (range 67-100), and 83\% in-hospital and 87\% at-home compliance (Wiskemann et al. 2011), while Shelton et al. reported $75 \%$ for the supervised intervention, though did not report for the self-directed intervention. Some studies had safety screening parameters, in which contraindication for exercise included platelet counts $<10$ and $20 \times 10^{9} / 1$ (Cunningham et al. 1986, Mello et al. 2003, Jarden et al. 2009; Wiskemann et al. 2011, Baumann et al. 2011), and haemoglobin $<5 \mathrm{~g} / \mathrm{dl}$ (Jarden et al. 2009), $<8$ (Wiskemann et al. 2011, Baumann et al. 2011), and $<10$ (Mello et al. 2003); temp $>38^{\circ} \mathrm{C}$ (Cunningham et al. 1986; Jarden et al. 2009; Wiskemann et al. 2011, Baumann et al. 2011), and adverse symptoms as bleeding, petecchiae, pain, nausea, dizziness. Baumann et al. interrupted training during cardio and nephrotoxic chemotherapy.

\subsection{Physiological outcomes - aerobic/endurance}

A mixed-type exercise program 5 days/week at moderate intensity during the entire hospitalization was able to maintain aerobic capacity, while the control group decreased, and this difference was highly significant $(\mathrm{p}<0.01)$ (Jarden et al. 2009). Another similar mixed-exercise program during hospitalization showed a significant decrease in aerobic endurance $(p=0.009)$ in the control group, but no significant difference between intervention and control groups (Baumann et al. 2011). A $12 \mathrm{wk}$. aerobic training program on cycle ergometer initiated between 9 and 92 months after HSCT showed cardiovascular effects through increased stroke volume $(\mathrm{p}<0.005)$ and decreased heart rate $(\mathrm{p}<0.005)$, with a decreased RPE ( $\mathrm{p}<0.005)$ (Carlson et al. 2006).

\subsection{Muscle strength}

Mello et al. combined aerobic (treadmill) and ROM exercise program initiated during hospitalization and continued into the outpatient facility over 6 weeks showed significant decrease in upper and lower extremity strength in the control group, however differences between intervention and control groups were not significant.

During hospitalization, four muscle strength tests (chest press 1 RM, leg extension 1 RM, elbow flexor and knee extensor Newton) decreased by $2-4 \%$ in the intervention group, while decreasing between $19-25 \%$ in the control group. This difference was significant $(\mathrm{p}<0.01)$ (Jarden et al. 2009). Baumann et al., however, did not find a significant difference between groups for muscle strength, but the pre to post muscle strength scores decreased significantly in the control group $(\mathrm{p}=0.022)$.

\subsection{Functional capacity}

Wiskemann et al. maintained the 6 minute walk distance (6MWD) in the intervention group, while the control group decreased and the intergroup difference was significant $(p=0.02)$. The 2 minute stair climb test in the intervention group decreased by $14 \%$ and for the control 
group 38\%, and the difference between groups was significant $(\mathrm{p}<0.01)$ (Jarden et al. 2009). A walking program did not show significant differences between groups for the Karnofsky score, though a subgroup analysis of the nonmyeloablative conditioned patients showed that this patient group decreased significantly less than the control group $(p=0.04)$ (DeFor et al. 2007). There were no significant differences for the 6MWD between a supervised and self directed intervention, still both groups significantly improved by $12 \%(\mathrm{p}<0.05)$ and $9.8 \%$ $(p<0.05)$, respectively (Shelton et al. 2009). Also, the supervised group improved the 50 foot walk time $(\mathrm{p}=0.05)$ and maintained other performance tests, though no significance between groups.

\subsection{Health-related quality of life}

A bed exercise study with relaxation breathing, ROM and stretching during hospitalization decreased depression (BDI) $\mathrm{p}=0.0001$ and anxiety (STAI) $\mathrm{p}=0.0001$ as compared to the control group (Kim and Kim 2006). An in- to out-patient walking program showed improvements in physical and emotional wellbeing on a self reported score from $1-10$, with 1 being very poor and 10 being very good. At discharge, physical wellbeing was better in the exercise group $(\mathrm{p}<0.01)$. Among the nonmyeloablative group, emotional wellbeing was better in the exercise group $(\mathrm{p}=0.02)$ at discharge and at 100 days, physical wellbeing was superior in the exercise group $(\mathrm{p}<0.01)$ (DeFor et al. 2007). A mixed exercise intervention during the entire hospitalization showed no difference in QoL and emotional wellbeing between groups (EORTC-QLQ-C30, FACT-An, HADS), though HRQOL was maintained in the intervention group at post testing, and there was significant improvement in emotional wellbeing at 3 and 6 months, $p=0.045$ and $p=0.012$, respectively (FACT-An) and significant decrease in anxiety at 3 and 6 months, $p=0.021$ and $p<0.0001$, respectively (HADS). The control group significantly decreased overall HRQOL $\mathrm{p}=0.0005$ (FACT-An) at post testing, and significantly reduced physical functioning $(p=0.004)$ and worsened three gastrointestinal symptoms (nausea and vomiting $(p=0.048)$, appetite loss $(p=0.004)$ and diarrhea ( $p=0.011$ ) (EORTC QLQ C-30) (Jarden et al. 2009). Wiskemann et al. study beyond discharge showed between group differences in favor of the intervention group in physical functioning $(p=0.03)$ (EORTC-QLQ-C30) and decreased depression $(p=0.05)$, though showed a significant increase in anxiety $(p=0.01)$ in the intervention group (HADS). Baumann et al. found no significant difference between groups on the EORTC-QLQ-C30, though the prepost differences in the intervention and control group decreased significantly for physical functioning ( $p=0.005$ and $p=0.002)$. Intervention group improved emotional state $(p=0.028)$, but again, no differences between groups (Baumann et al. 2011). Carlson et al.'s out-patient endurance program significantly improved intergroup vigor scores $(p<0.001)$ on POMS.

\subsection{Treatment-related symptoms}

There was a decreased symptom prevalence in diminished concentration, memory loss, nausea and nervousness $(\mathrm{p}<0.01)$ and decreased symptom severity in fatigue, loss of appetite, sleep difficulties and nausea $(\mathrm{p}<0.05)$ on the SCT-SAS scale (Jarden et al. 2009). Further, diarrhea was significantly decreased (EORTC-QLQ-C30) $(\mathrm{p}=0.014)$ (Jarden et al. 2009). Symptom cluster analyses revealed a significant decrease in symptom severity in gastrointestinal, cognitive, functional and mucositis clusters over time and up to 6 months after allo-HSCT $(\mathrm{p}<0.01)$. Wiskemann et al. found a significant decrease between groups in both general and physical fatigue $(p=0.009, p=0.01)$ MFI and a significant decrease in fatigue 
$(\mathrm{p}=0.01)$ (POMS). Baumann et al. was unable to show between group differences in fatigue scores, but the control group increased fatigue at post testing $(\mathrm{p}=0.046)$. Carlson et al. showed a significant decrease in fatigue $(\mathrm{p}<0.001)(\mathrm{BFI}$ and FACT-F).

\subsection{Medical related outcomes}

Cunningham et al. did not find significant changes in body composition, though a decreased creatinine excretion in the intervention group (Cunningham et al. 1986). Kim et al. tested a bed exercise effect on lymphocyte counts, and reported no significant differences between groups, however there was an interaction between groups and times $(p=0.031)$, there was also a decrease in lymphocyte count in the control group $(p<0.05)$. Jarden et al. reported the intervention group as receiving fewer days of TPN $(p=0.019)$ with no changes in BMI between groups at post testing. There were no other differences between groups regarding hospitalization days, bone marrow engraftment days, days with fever, and though there was a 19\% difference in the incidence of GvHD favoring the intervention group, this was not statistically different. Defor et al. and Inoue et al. showed no difference in days of hospitalization between groups, but Inoue et al. showed that the degree of physical activity had a negative correlation with the duration of hospitalization $(\mathrm{r}=-.71 ; \mathrm{p}=0.0071)$.

\subsection{Methodological quality of the studies}

Seven studies were designed as randomized trials (Cunningham et al. 1986; Mello et al. 2003; Kim and Kim 2006; Defor et al. 2007; Jarden et al. 2009; Shelton et al. 2009; Baumann et al. 2011), one study allocated through the minimization method (Wiskeman et al. 2011), one study was a convenience sample studying the effect of the same exercise intervention on two different allo-HSCT treatment groups (myeloablative or nonmyeloablative conditioning regime) (Inoue et al. 2010) and one study did not have a control group (Carlson et al. 2006). Further, Shelton et al. studied the effect of two different interventions (supervised vs. self directed) in the outpatient/home setting. The control group was described in most studies as receiving standard or usual care, including either no formal training or the hospital units' standard physical therapy (PT). Generally, standard PT was described as being introduced later during hospitalization, i.e. after stem cell infusion, and at less frequent intervals and lower intensity levels. The study arms were not similar at baseline in two (Kim and Kim 2006; Baumann et al. 2011) of the eight groups in which there was an intervention and control group present. The control group in Kim et al. had a significant higher lymphocyte level at baseline compared to the intervention group and Baumann et al. had twice as many males as females in the exercise group as compared to the control group at baseline. All studies reported the eligibility criteria to which the study population was chosen. Only one study stated that the outcome assessor was blinded (DeFor et al. 2007). In the relevant studies, none reported blinding of the exercise trainer or the patients. Two studies reported performing intention-to-treat analyses (Jarden et al. 2009; Wiskemann et al. 2011).

\section{Summary}

This is the first literature review of exercise-based interventions in the allo-HSCT context. The purpose of this systematic review was to summarize the exercise-based rehabilitative interventions in adults with haematological disease undergoing allogeneic hematopoetic 
stem cell transplantation (allo-HSCT) on feasibility and safety, and effectiveness related to physical and functional capacity, health related quality of life, treatment-related symptoms and medical related outcomes. To date, 10 intervention studies and 13 articles have been published that incorporated exercise-based regimes in the allo-HSCT context, and though we have found encouraging and important results, making direct trial comparisons can be a challenge due to the small sample sizes, the wide range of different primary and secondary outcomes and measurements, varying types of interventions, and different start and end points, duration, frequency and intensity of the different exercise components. Most of the studies in this review were randomized trials, however, control groups received varying standard care regimes, and there was a lack of outcome assessor blinding, trainer blinding and patient blinding which decreases the general methodological quality of the studies. Taking these methodological limitations into consideration, this review however finds important results pertinent to the allo-HSCT clinical setting.

The results suggest that exercise interventions are feasible and safe. No study reported adverse events as a direct result of testing or exercising, though not all studies reported safety. Five studies reported safety screening parameters, which may have contributed to patients being able to exercise safely. Of the five studies that reported compliance rates, it would suggest that patients are capable of participating adequately in a daily exercise program during and after allo-HSCT. Two mixed type exercise studies implemented during the entire hospitalization suggest a stabilization in aerobic endurance during hospitalization (Jarden et al. 2009; Baumann et al. 2011), and one 12 week out-patient endurance study found significant positive cardiovascular effects (Carlson et al. 2006). In regards to muscle strength, mixed type exercise during hospitalization (Baumann et al. 2011; Jarden et al. 2009) and continuing in the outpatient context (Mello et al. 2003) showed significant muscle strength decreases in control group, but only one study found significant differences between groups (Jarden et al. 2009) suggesting that the loss of muscle strength was minimized. Mixed type exercise during hospitalization (Jarden et al. 2009) and continued after discharge (Wiskemann et al. 2011) significantly decreased loss of function (2 minute stair climb) (Jarden et al. 2009) and significantly maintained function (6MWT) (Wiskemann et al. 2011). DeFor et al.'s walking program during and after discharge did not show significant differences between groups for Karnofsky score, though a subgroup analysis of the nonmyeloablative group showed a significant reduction in loss of performance in the intervention group. (DeFor et al. 2007). Both supervised and self directed mixed type exercise in the post HSCT was shown to improve function significantly on the 6MWD and for the supervised group improvement was reported for the 50 foot walk time (Shelton et al. 2009). A mixed type low intensity exercise program during hospitalization significantly decreased depression (BDI) and anxiety as compared to the control group (Kim and Kim 2006), while two mixed-type moderate intensity exercise programs during hospitalization did not show a significant effect on HR-QoL (Baumann et al. 2011, Jarden et al. 2009), but Wiskemann et al.'s mixed type exercise that continued after discharge showed a significant improvement in physical functioning and decreased depression, but also a significant increase in anxiety (Wiskemann et al. 2011). DeFor's in- to out-patient walking program reported significant improvements in emotional wellbeing among the nonmyeloablative patient group at hospital discharge and by 100 days, physical wellbeing was significantly improved. Carlson et al.'s 12 week out-patient endurance program significantly increased vigor. There was a significant longitudinal decrease in prevalence and intensity of several 
symptoms and symptom clusters, including fatigue up to 6 months (Jarden et al. 2009) and in two studies exercising after discharge, a significant decrease in fatigue scores was reported (Wiskemann et al. 2011, Carlson et al. 2006). Hospital or treatment-related outcomes as body composition or immunological and infectious parameters i.e. lymphocyte counts, days to bone marrow engraftment, days with fever, incidence of GvHD., number of transfusions received) was not affected by exercise. One exercising group received significantly fewer days of TPN as compared to the control group (Jarden et al. 2009). There was no effect on duration of hospitalization (Inoue et al. 2010, Jarden et al. 2009, Defor et al. 2007), though Inoue et al. reported that the level of physical activity had a negative correlation with the number of hospitalization days (Inoue et al. 2010).

It is suggested in recent literature that the optimal training program for persons with cancer combine both aerobic and muscle strength training (Neiman \& Courneya, 2006, Courneya \& Friedenreich, 2011). A review from 2008 of 15 exercise trials in the in-patient and out-patient HSCT setting, included patients in the allo-HSCT and HD-SCS context and resulted in tentative recommendations (Wiskemann \& Huber, 2008): mixed exercise: endurance (up to daily) and resistance training (2-3 x/wk)), from 10 - 30 minutes at moderate intensity (BORG scale $12-14,70-80 \%$ maximum HR) before, during and after hospitalization. In Liu et al. literature review from 2009 of physical exercise interventions in hæmatological cancer patients suggested it feasible to conduct exercise in this patient population, but concluded that there was a lack in methodological quality in the physical exercise studies and therefore effectiveness could not be established (Liu et al. ). Recommendations based on a more recent review from 2011 of patients with mixed hematologic disease propose 'supervised' exercise during and after hematological cancer treatments 2 to 5 days per week, with adjustment for health conditions. Further, a combination of aerobic and resistance exercise is suggested, with a varying intensity between $40-70 \%$ of maximum heart rate and full body resistance exercises at 8-12 reps and 2-3 sets with slow progression over time. Health and neutropenic screening for exercise participation is also recommended according to Jones et al. (Battaglini 2011).

Exercise recommendations, however for patients during and after hospitalization for specifically allo-HSCT have not been developed, and in order to determine the appropriate and optimal exercise prescription / intervention for patients undergoing allo-HSCT, trials in the allo-HSCT context were examined in this review for type, duration, frequency and intensity. Taken the methodological limitations into consideration, a partly to fully supervised and daily, mixed-type exercise (aerobic and resistant exercises, also ROM and stretching) at moderate intensity (70-75\% MHR) started at least prior to conditioning and carried out during allo-HSCT is feasible and can maintain or decrease loss of aerobic capacity, muscle strength and function at hospital discharge. However, continuing the program after hospital discharge had further physical, functional and symptom related benefits (decrease fatigue, reduced depression). Attaining positive results require a relatively high compliance rate, over $85 \%$. Therefore, screening parameters and contraindication for training criteria should be instituted to not only keep the patient safe, but also enable adequate participation in the program. Based on this review, it can be suggested that postponement or modification of training include: platelets $<20 \times 10^{9} /$, haemoglobin $<5-8 \mathrm{~g} / \mathrm{l}$, temp $>38^{\circ} \mathrm{C}$ and adverse symptoms as bleeding, petecchiae, pain, nausea, dizziness. It is not clear from this review, whether training during conditioning inkl. cardio and nephrotoxic chemotherapy should be postponed, and to what extent, that is, during active infusion or hours/days following chemotherapy. We may also consider 
incorporation of low intensity exercise as relaxation breathing or progressive relaxation in the program, especially when a higher exercise intensity level is not possible (Kim and Kim, 2006; Jarden et al. 2009). Psychosocial, educational and motivational approaches may be integrated to maintain compliance levels, support exercise motivation and efficacy and increase independent activity and lifestyle changes.

\section{Conclusion and future research}

This chapter is a systematic review of the rehabilitation research carried out in the alloHSCT context during the past 25 years. These findings, despite a number of methodological issues, indicate positive physiological and emotional benefits from exercise in patients during and after allo-HSCT. Exercise during treatment may help patients decrease loss of or maintain aerobic and functional capacity, and muscle strength, and when exercise is continued or instituted in the outpatient/home context there are improvements in aerobic and functional capacity. These results also indicate that exercise-based interventions have multidimensional benefits, including maintaining or improving HRQOL and reducing the most persistent treatment-related symptoms, especially fatigue. This review provides general guidelines for exercise in the allo-HSCT context. However, with improved methodological approaches, future research may provide clinicians with more specific rehabilitation guidelines.

\subsection{Future research}

Future studies are encouraged to institute certain methodological stringencies, including inclusion of homogenous groups (same diagnosis or treatment group), larger patient populations, perhaps, multi-institutional studies, randomized designs that clearly describe treatment allocation and stratification methods, as well as details regarding the control group. Further, point estimates for primary outcomes, effect size calculations, as well as Intention-to-Treat analyses are recommended. When and if possible, an effort to blind outcome assessors, data entry keyers and statisticians would improve methodological quality. It is also important that future studies justify the chosen intervention and clearly describe the individual exercise components duration, intensity and frequency as well as screening parameters for intervention participation, and lastly, documentation of compliance rates in order to properly evaluate the effect of the intervention. Decisions regarding test time-points and the most relevant and comprehensive outcome measurements need to be associated with challenges directly related to allo-HSCT. Therefore, GvHD, treatment related symptoms i.e. fatigue, insomnia, pain, gastrointestinal complaints, skin and bodily changes, poor physical, functional and muscle capacity, low levels of physical activity and decreased bone density, low Vitamin D levels and reduced HRQOL including problems with sexuality, body image, social wellbeing and job function need to be considered in this treatment group. More studies are needed that examine the entire treatment trajectory and continue well into the out-patient and home setting. Research that aims to promote multidimensional benefits may consider multimodal interventional designs that combine physical exercise with other psychosocial and educational approaches. Additionally the role of vitamin D and exposure to sunlight in combination with physical exercise on bone health, function and general wellbeing may be warranted. Further, there is 
a need to study the patients' own experience as a participant in an exercise-based intervention in order to develop programs that are tailored to fit the needs of patients during and after allo-HSCT. Finally, translational intervention studies are needed that support and improve the ability of patients to cope with their life situation during treatment, as well as to function optimally after allo-HSCT in daily life, including return to employment.

\section{Conflict of interest}

The author declares no conflict of interest.

\section{Acknowledgements}

I thank Anders Larsen (Information specialist - The University Hospital's Centre for Nursing and Care Research, Copenhagen Denmark) for verifying and assisting with the literature search strategy. I would also like to thank Kristine Marie Jarden (Research assistant - University of Southern Denmark) for her assistance in manuscript preparation.

\section{References}

Andrykowski MA, Breiner CB, Altmaier EM. (1995) Quality of life following bone marrow transplantation: findings from a multicenter study. Br J Cancer; 71:1322-9.

Baker F, Marcellus D, Zabora J, Polland A, Jodrey D. (1997) Psychological distress among adult patients being evaluated for bone marrow transplantation. Psychosomatics 1997;38:10-19

Battaglini CL. (2011) Physical Activity and hematological Cancer Survivorship. Physical Activity and Cancer, Recent Results in Cancer Research 186, DOI: 10.1007/978-3-64204321-7_12, Springer-Verlag Berlin Heidelberg, 275-304.

Baumann FT, Zopf EM, Nykamp E, Kraut L, Schüle K, Elter T, Fauser AA, Bloch W. (2011) Physical activity for patients undergoing an allogenic hematopoietic stem cell transplantation: benefits of a moderate exercise intervention. European Journal of Haematology; accepted article: 10.1111/j.1600-0609.2011.01640.x

Bearman SI, Applebaum FR, Buckner CD. (1988) Regimen-related toxicity in patients undergoing bone marrow transplantation. J Clin Oncol;6:1562-68.

Bevans MF, Mitchell SA, Marden S. (2008) The symptom experience in the first 100 days following allogeneic hematopoietic stem cell transplantation (HSCT).Support Care Cancer;16:1243-54.

Broers S, Kaptein AA, Le Cessie S, Fibbe W, Hengeveld MW. (2000) Psychological functioning and quality of life following bone marrow transplantation: a 3-year follow-up study. J Psychosom Res;48:11-21.

Carlsen K, Oksbjerg Dalton S, Frederiksen K, Diderichsen F, Johansen C. (2008) Cancer and the risk for taking early retirement pension: a Danish cohort study. Scand J Public Health;36(2):117-25.

Carlson LE, Smith D, Russell J, Fibich C, Whittaker T. (2006) Individualized exercise program for the treatment of severe fatigue in patients after allogeneic 
hematopoietic stem-cell transplant: a pilot study. Bone Marrow Transplant;37:94554.

Coleman EA, Coon S, Hall-Barrow J, Richards K, Gaylor D, Stewart B. (2003) Feasibility of exercise during treatment for multiple myeloma. Cancer Nurs 2003;26:410-9.

Conn V, Hafdahl A, Porock D, McDaniel R, Nielsen P. (2006) A meta-analysis of exercise interventions among people treated for cancer. Support Care Cancer; 14:699-712.

Courneya KS, Friedenreich (2011) Physical Activity and Cancer, Recent Results in Cancer Research 186, DOI: 10.1007/978-3-642-04321-7_12, Springer-Verlag Berlin Heidelberg.

Courneya KS, Keats MR, Turner AR. (2000) Physical exercise and quality of life in cancer patients following high dose chemotherapy and autologous bone marrow transplantation. Psychooncology;9:127-36.

Cunningham BA, Morris G, Cheney CL, Buergel N, Aker SN, Lenssen P. (1986) Effects of resistive exercise on skeletal muscle in marrow transplant recipients receiving total parenteral nutrition. J Parenter Enteral Nutr;10:558-563.

Danaher Hacker E, Larson JL, Peace D. (2011) Exercise in Patients Recieving Hematopoietic Stem Cell Transplantation: Lessons Learned and Results From a Feasibility Study. Oncology Nursing Forum;38:216-223.

Danaher Hacker E, Ferrans C, Verlen E, Ravandi F, Van Besien K, Gelms J, Dieterle N. (2006) Fatigue and Physical activity in patients undergoing hematopoietic stem cell transplant. Oncol Nurs Forum;33:615-24.

Decker WA, Turner-McGlade J, Fehir KM. (1989) Psyhcological aspects and the physiological effects of a cardiopulmonary exericse program in patients undergoing bone marrow transplantation for acute leukemia. Transplant Proc 21;21(1Pt3):3068-3069.

de Boer AG, Verbeek JH, Spelten ER, Uitterhoeve AL, Ansink AC, de Reijke TM, Kammeijer M, Sprangers MA, van Dijk FJ. (2008) Work ability and return-to-work in cancer patients. Br J Cancer;98(8):1342-7.

DeFor TE, Burns LJ, Gold EM, Weisdorf DJ. (2007) A randomized trial of the effect of a walking regimen on the functional status of 100 adult allogeneic donor hematopoietic cell transplant patients. Biol Blood Marrow Transplant;13:94855.

Devergie A. Graft vs. host disease. (2004) In: Apperley J, Carrerras E, Gluckman E, Gratwohl A, Masszi T, eds. The EBMT Handbook 2004 revised edition: haemopoietic stem cell transplantation. Maastricht: European Group for Blood and Marrow Transplantation; 63-168.

Dimeo F, Bertz H, Finke J, Fetscher S, Mertelsmann R, Keul J. (1996) An aerobic exercise program for patients with haematological malignancies after bone marrow transplantation. Bone Marrow Transplant;18:1157-60.

Dimeo F, Fetscher S, Lange W, Mertelsmann R, Keul J. (1997) Effects of aerobic exercise on the physical performance and incidence of treatment related complications after high dose chemotherapy. Blood;90:3390-4. 
Dimeo F, Schwartz S, Fietz T, Wanjura T, Boning D, Thiel E. (2003) Effects of endurance training on the physical performance of patients with hematological malignancies during chemotherapy. Support Care Cancer;11:623-628.

Dimeo F, Stieglitz RD, Novelli-Fischer U, Fetscher S, Keul J. (1999) Effects of physical activity on the fatigue and psychologic status of cancer patients during chemotherapy. Cancer;85:2273-7.

Fife BL, Huster GA, Cornetta KG. (2000) Longitudinal study of adaptation to the stress of bone marrow transplantation. J Clin Oncol;29:1539-49.

Frassoni F. Stem Cell Transplantation in adults. (2004) In: Apperley J, Carrerras E, Gluckman E, Gratwohl A, Masszi T, eds. The EBMT Handbook 2004 revised edition: haemopoietic stem cell transplantation. Maastricht: European Group for Blood and Marrow Transplantation; 2004. p. 239-54.

Gratwohl A, Baldomero H, Horisberger B, Schmid C, Passweg J, Urbano-Ispizua A. (2002) Current trends in hematopoietic stem cell transplantation in Europe. Blood; 100:2374-86.

Grulke N, Albani C, Bailer H. (2011) Quality of Life in patients before and after haematopoietic stem cell transplantation measured with the European Organization for Research and Treatment of Cancer (EORTC) Quality of Life Core Questionnaire QLQ-C30. Bone Marrow Transplant, accepted 28 March 2011;1-10.

Hayes S, Davies PS, Parker T, Bashford J. (2003) Total energy expenditure and body composition changes following peripheral blood stem cell transplantation and participation in an exercise program. Bone Marrow Transplant;31:331-8.

Hayes S, Davies PS, Parker T, Bashford J, Newman B. (2004) Quality of life changes following peripheral blood stem cell transplantation and participation in a mixed-type, moderate-intensity, exercise program. Bone Marrow Transplant; 33:553-8.

Hayes SC, Rowbottom D, Davies PS, Parker TW, Bashford J. (2004) Immunological changes after cancer treatment and participation in an exercise program. Med Sci Sports Exerc; 35:2-9.

Hayes SC, Davies PS, Parker TW, Bashford J, Green A. (2004) Role of a mixed-type, moderate intensity exercise programme after peripheral blood stem cell transplantation. Br J Sports Med;38:304-9.

Hings IM, Severeson R, Filipovich AH. (1994) Treatment of moderate and severe acute graftversus host disease after allogeneic bone marrow transplantation. Transplantation; 58:437-42.

Inoue J, Ono R, Okamura A, Matsui T, Taekoshi H, Miwa M, Kurosaka M, Saura R, Shimada T. (2010) The impact of Early Rehabilitation on the Duration of Hospitalization in Patients After Allogenic Hematopoietic Stem Cell Transplantation. Transplantation Proceedings; 42: 2740-2744.

Jarden M, Baadsgaard MT, Hovgaard DJ, Boesen E, Adamsen L. (2009) A randomized trial on the effect of a multimodal intervention on physical capacity, functional performance and quality of life in adult patients undergoing allogeneic SCT. Bone Marrow Transplantation;43(9):725-737. 
Jarden M, Nelausen K, Hovgaard D, Boesen E, Adamsen L. (2009) The effect of a multimodal intervention on treatment-related symptoms in patients undergoing hematopoietic stem cell transplantation: A randomized controlled trial. Journal of pain and symptom management;38(2):174-190.

Jarden M, Hovgaard D, Boesen E, Quist M, Adamsen L. (2007) Pilot study of a multimodal intervention: mixed-type exercise and psychoeducation in patients undergoing allogeneic stem cell transplantation. Bone Marrow Transplantation; 40:793-800.

Kalo J, Agergård J, Aadahl M, Visby R, Halkjær Kristensen J, Jacobsen N. (2007) Fatigue in hematological patients treated with allogeneic stem cell transplantation. J Danish Med Assoc;169:3194-7.

Kim SD, Kim HS. (2006) A series of bed exercises to improve lymphocyte count in allogeneic bone marrow transplantation patients. Eur J Cancer Care (Engl); 15:453-7.

Kim S-D, Kim H-S. (2005) Effects of a relaxation breathing exercise on anxiety, depression, and leukocyte in hemopoietic stem cell transplantation patients. Cancer Nursing; 28(1):79-83.

Kirchhoff AC, Leisenring W, Syrjala KL. (2010) Prospective predictors of return to work in the 5 years after hematopoietic cell transplantation. J Cancer Surviv;4(1)3344.

Knutsen KV, Brekke M, Gjelstad S, Lagerløv P. (2010) Vitamin D status in patients with musculoskeletal pain, fatigue and headache: a cross-sectional descriptive study in a multi-ethnic general practice in Norway.Scand J Prim Health Care. 28(3):166-71.

Larsen J, Nordstrom G, Ljungman P, Gardulf A. (2007) Factors associated with poor general health after stem-cell transplantation. Support Care Cancer;15:849-57.

Massenkeil G, Fiene C, Rosen O, Michael R, Reisinger W, Arnold R. (2001) Loss of bone mass and vitamin $\mathrm{D}$ deficiency after hematopoietic stem cell transplantation: standard prophylactic measures fail to prevent osteoporosis Leukemia;15(11):1701-5

McQuellon RP, Russell GB, Rambo TD, Craven BL, Radford Perry JJ, Cruz J, Hurd DD. (1998) Quality of life and psychological distress of bone marrow transplant recipients: the 'time trajectory' to recovery over the first year. Bone Marrow Transplant; 21:477-86.

Mello M, Tanaka C, Dulley FL. (2003) Effects of an exercise program on muscle performance in patients undergoing allogeneic bone marrow transplantation. Bone Marrow Transplant; 32:723-8.

Mitchell SA, Leidy NK, Mooney KH, Dudley WN, Beck SL, LaStayo PC, Cowen EW, Palit P, Comis LE, Krumlauf MC, Avila DN, Atlam N, Fowler DH, Pavletic SZ. (2010) Determinants of functional performance in long-term survivors of allogeneic hematopoietic stem cell transplantation with chronic graft-versus-host disease (cGVHD). Bone Marrow Transplant;45(4)Epub 2009.

Moher D, Liberati A, Tetzlaff J, Altman DG, The PRISMA Group (2009) Preferred Reporting Items for Systematic Reviews and Meta-Analyses: The PRISMA Statement. PLoS Med 6(7): e1000097. doi:10.1371/journal.pmed.1000097 
Molassiotis A, Morris PJ. (1997) Suicide and suicidal ideation after marrow transplantation. Bone Marrow Transplant; 19:87-90.

Molassiotis A, Morris PJ. (1999) Quality of life in patients with chronic myeloid leukemia after unrelated donor bone marrow transplantation. Cancer Nurs; 22:340-9.

Nieman DC, Courneya KS. (2006) Immunological conditions. In: American College of Sports Medicine. ACSM's Resource Manual For Guidelines For Exercise Testing and Prescription. 5th ed. Philadelphia: Lippincott Williams \& Wilkins; 2006. p. 528-542.

Persoon S, Kersten MJ, ChinAPaw M JM, Buffart LM, Burghout H, Schep G, Brug J, Nollet F. (2010) Design of the Exercise Intervention after Stem cell Transplantation (EXIST) study: a randomized controlled trial to evaluate the effectiveness and cost-effectiveness of an individualized high intensity physical exercise program on fitness and fatigue in patients with multiple myeloma or (non-) Hodgkins lymphoma treated with high dose chemotherapy and autologous stem cell transplantation. BMC; 10:671 http://www.biomedcentral.com/1471-2407/10/671.

Portenoy RK, Thaler HT, Kornblith AB, Lepore JM, Friedlander-Klar H, Coyle N, SmartCurley T, Kemeny N, Norton L, Hoskins W, et al. (1994) Symptom prevalence, characteristics and distress in a cancer population. Qual Life Res;3:183-9.

Prieto JM, Atala J, Blanch J, Carreras E, Rovira M, Cierera e, Gasto C. (2005) Patientrated emotional and physical functioning among hematologic cancer patients during hospitalization for stem-cell transplantation. Bone Marrow Transplant; 35(3):307-14.

Roy J, McGlave PB, Filipovich AH. (1992) Acute graft-versus-host disease following unrelated donor marrow transplantation: failure of conventional therapy. Bone Marrow Transplant;10:77-82.

Schulz-Kinderman F, Hennings U, Ramm G. (2002) The role of biomedical and psychosocial factors for the prediction of pain and distress in patients undergoing high-dose therapy and BMT/PBSCT. Bone Marrow Transplant;29:341-51.

Schmitz KH, Holtzmann J, Courneya K, Masse LC, Duval S, Kane R. (2005) Controlled physical activity trials in cancer survivors: a systematic review and meta-analysis. Cancer Epidemiol Biomarkers Prev;14:1588-1595.

Schmitz KH, Courneya KS, Matthews C, Demark-Wahnefried W. Galvao DA, Pinto BM, Irwin ML, Wolin KY, Segal RJ, Lucia A, Schneider CM, von Gruenigen VE, Schwartz AL. (2010) American College of Sports Medicine Roundtable on Exercise Guidelines for Cancer Survivors: Special Communications - Roundtable Consensus Statement, Medicine \& Science in Sports \& Exercise, DOI:10.1249/ MSS.0b013e3181e0c112;1409-1423

Shelton ML, Lee JQ, Morris GS, Massey PR, Kendall DG, Munsell MF, Anderson KO, Simmonds MJ, Giralt SA. (2010) A randomized control trial of a supervised versus a self-directed exercise program for allogeneic stem cell transplant patients. PsychoOncology;18: 353-359. 
So WK, Dodson J, Tai JW. (2003) Fatigue and quality of life among Chinese patients with hematologic malignancy after bone marrow transplantation. Cancer Nurs; 26:211-9.

Sproat L, Bolwell B, Rybicki L, Dean R, Sobecks R, Pohlman B, Andresen S, Sweetenham J, Copelan E, Kalaycio M. (2011) Vitamin d level after allogeneic hematopoietic stem cell transplant. Biol Blood Marrow Transplant. 17(7):1079-83.

Syrjala KL, Chapko MK, Vitaliano PP, Cummings C, Sullivan KM. (1993) Recovery after allogeneic marrow transplantation: prospective study of predictors of longterm physical and psychosocial functioning. Bone Marrow Transplant;11:31927.

Weisdorf D, Haake R, Blazar B. (1990) Treatment of moderate/severe acute graft-versushost disease after allogeneic bone marrow transplant: an analysis of clinical risk features and outcome. Blood; 75:1024-30.

Wilson RW, Jacobsen PB, Fields KK. (2005) Pilot study of a home-based aerobic exercise program for sedentary cancer survivors treated with hematopoietic stem cell transplantation. Bone Marrow Transplant;35:721-7.

Wiskemann J, Huber G. (2008) Physical exercise as adjuvant therapy for patients undergoing hematopoietic stem cell transplantation. Bone Marrow Transplant; 41:321-9.

Wiskemann J, Dreger P, Schwerdtfeger R, Bondong A, Huber G, Kleindienst N, Ulrich CM, Bohus M. (2010) Effects of a partly self-administered exercise program before, during and after allogeneic stem cell transplantation. Blood; 117(9):26042613. 


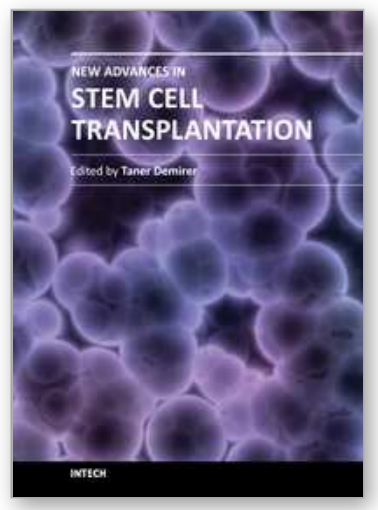

\author{
New Advances in Stem Cell Transplantation \\ Edited by Prof. Taner Demirer
}

ISBN 978-953-51-0013-3

Hard cover, 582 pages

Publisher InTech

Published online 24, February, 2012

Published in print edition February, 2012

This book documents the increased number of stem cell-related research, clinical applications, and views for the future. The book covers a wide range of issues in cell-based therapy and regenerative medicine, and includes clinical and preclinical chapters from the respected authors involved with stem cell studies and research from around the world. It complements and extends the basics of stem cell physiology, hematopoietic stem cells, issues related to clinical problems, tissue typing, cryopreservation, dendritic cells, mesenchymal cells, neuroscience, endovascular cells and other tissues. In addition, tissue engineering that employs novel methods with stem cells is explored. Clearly, the continued use of biomedical engineering will depend heavily on stem cells, and this book is well positioned to provide comprehensive coverage of these developments.

\title{
How to reference
}

In order to correctly reference this scholarly work, feel free to copy and paste the following:

M. Jarden (2012). A Systematic Review of Nonpharmacological Exercise-Based Rehabilitative Interventions in Adults Undergoing Allogeneic Hematopoietic Stem Cell Transplantation, New Advances in Stem Cell Transplantation, Prof. Taner Demirer (Ed.), ISBN: 978-953-51-0013-3, InTech, Available from: http://www.intechopen.com/books/new-advances-in-stem-cell-transplantation/exercise-based-rehabilitativeinterventions-in-adults-with-haematological-disease-undergoing-allogen

\section{INTECH}

open science | open minds

\author{
InTech Europe \\ University Campus STeP Ri \\ Slavka Krautzeka 83/A \\ 51000 Rijeka, Croatia \\ Phone: +385 (51) 770447 \\ Fax: +385 (51) 686166 \\ www.intechopen.com
}

\author{
InTech China \\ Unit 405, Office Block, Hotel Equatorial Shanghai \\ No.65, Yan An Road (West), Shanghai, 200040, China \\ 中国上海市延安西路65号上海国际贵都大饭店办公楼 405 单元 \\ Phone: +86-21-62489820 \\ Fax: +86-21-62489821
}


(C) 2012 The Author(s). Licensee IntechOpen. This is an open access article distributed under the terms of the Creative Commons Attribution 3.0 License, which permits unrestricted use, distribution, and reproduction in any medium, provided the original work is properly cited. 